\title{
Inhibitory Effect of (2R)-1-(1-Benzofuran-2-yl)-N-propylpentan-2-amine on Lung Adenocarcinoma
}

\author{
Zsolt Mervai $^{1}$ • Andrea Reszegi ${ }^{1} \cdot$ Ildikó Miklya $^{2} \cdot$ József Knoll $^{2} \cdot$ Zsuzsa Schaff $^{3} \cdot$ Ilona Kovalszky $^{1} \cdot$ Kornélia Baghy $^{1}$ (ID
}

Received: 15 December 2018 / Accepted: 15 January 2019/Published online: 8 February 2019

(C) The Author(s) 2019

\begin{abstract}
BPAP is a potent enhancer substance with catecholaminergic and serotoninergic activity in the brain. It was discovered that it is also effective against certain types of experimental cancers, showing the most promising results in case of lung cancer. That is why we tested its efficacy in two different doses in a newly developed EGFR wild type mouse lung adenocarcinoma xenograft model. Experiments were conducted on FVB/N and SCID mouse strains treated with low and high dose of BPAP. Body weight, survival, and tumor volumes were recorded. Furthermore, the activity of major signaling pathways of NSCLC such as MAPK and Akt/mTOR as well as cell cycle regulation were determined. Significant inhibition of tumor growth was exerted by both doses, but the mechanism of action was different. High dose directly inhibited, whereas low dose activated the main signaling pathways. Exposure to low dose BPAP resulted in elevated activity of the mTOR pathway together with $\mathrm{p} 16^{\mathrm{INK}}$-induced cell cycle arrest, a typical feature of geroconversion, a senescent state characterized by loss of cell proliferation. Finally the events culminated in cell cycle inhibition point in case of both doses mirrored by the decrease of cyclin D1, CDK4 and PCNA. In addition, BPAP treatment had a beneficial effect on bodyweight suggesting that the compound at least in part is able to compensate the cancer-related wasting. In view of the low toxicity and confirmed antitumor effect of BPAP against experimental lung adenocarcinoma, this novel compound deserves further attention.
\end{abstract}

Keywords BPAP $\cdot$ Lung adenocarcinoma $\cdot$ Cancer $\cdot$ Tumor inhibition $\cdot$ FVB/N $\cdot$ Geroconversion

\section{Introduction}

The phenethylamine derivative (-)-deprenyl (also known as selegiline) gained attention in the 1970s when its ability to block MAO-B enzyme [1] was confirmed and was hence the first to be used in the treatment of Parkinson's disease [2]. Longevity studies showed that deprenyl can prolong the lifespan of rats, mice and

József Knoll is deceased. This paper is dedicated to his memory.

Electronic supplementary material The online version of this article (https://doi.org/10.1007/s12253-019-00603-6) contains supplementary material, which is available to authorized users.

Kornélia Baghy

baghy.kornelia@med.semmelweis-univ.hu

1 1st Department of Pathology and Experimental Cancer Research, Semmelweis University, Üllői út 26., Budapest H-1085, Hungary

2 Department of Pharmacology and Pharmacotherapy, Semmelweis University, Budapest, Hungary

3 2nd Department of Pathology, Semmelweis University, Budapest, Hungary beagle dogs when given in a daily dose of $0.25 \mathrm{mg} / \mathrm{kg}$ [3-5]. Later on 1-phenyl-2-propylaminopentane (PPAP) was synthetized, lacking the MAO inhibitory effect but still being a potent enhancer of catecholaminergic signaling in the central nervous system [6]. Based on above results, a tryptamine derived new compound, (2R)-1-(1-Benzofuran-2-yl)-N-propylpentan-2amine (BPAP) was created, capable of potentiating catecholaminergic and serotonergic activity in the brain [7]. BPAP has been shown to have neuroprotective and memory stimulatory effects similar to those of deprenyl but without the ability to inhibit the MAO-B enzyme [8].

Both BPAP and deprenyl are capable of exerting their effects in a very low concentration range [9]. The impact on learning skills and lifespan of long-term deprenyl and BPAP treatment at low concentration ranges was monitored in a longevity study carried out on Wistar rats. Both molecules exhibited a lifespanextending effect, but BPAP showed more promising results [10]. It was noticed that significantly less spontaneous fibrosarcomas developed in the treated groups than in the control group [11]. Based on these observations, we tested the effects of lowdose BPAP treatment in different tumor models. 
In an in vivo model of colon cancer with liver metastasis, BPAP significantly reduced the number of metastasis [11]. In addition, BPAP was tested in other tumor models as well: xenograft models of mouse colon carcinoma and lung adenocarcinoma and in a primary hepatocarcinogenesis experiment induced by diethylnitrosamine in mice. The most promising results were obtained in the lung tumor model established from a FVB/N strain, in which lung adenocarcinomas developed after exposure to single doses of diethylnitrosamine [12].

Lung cancer is the most common cancer in Europe and the United States claiming the largest number of lives [13, 14]. Histologically, the disease is divided into two major classes: small cell lung cancer (SCLC) and non-small cell lung cancer (NSCLC) [15]. The latter is the more common and in the United States $85 \%$ of lung cancers are NSCLC [15]. In the last decade, adenocarcinomas became the dominant representative within NSCLC [16].

It is not unprecedented that a molecule effective in a nonmalignant disorder is found to inhibit certain types of cancers [17]. Several nonsteroidal anti-inflammatory drugs, statins and other types of anti-psychotic drugs were shown to have anti-tumor effect [17].

In the present work, we aimed to examine the effects and mechanism of action of BPAP in lung adenocarcinomas.

\section{Materials and Methods}

\section{Animals and Treatments}

All animal experiments were conducted according to the ethical standards of the Animal Health Care and Control Institute of Csongrád County, Hungary and the protocol was approved by their Committee (permit No. XVI/03047-2/2008). Animals were obtained from the animal facility of the $1 \mathrm{st}$ Department of Pathology and Experimental Cancer Research of Semmelweis University (Budapest, Hungary).

To examine the effects of BPAP on lung adenocarcinoma, a subcutaneous mouse tumor model was applied [12]. To this end, a total of $45 \mathrm{FVB} / \mathrm{N}$ male mice at the age of 8 weeks were utilized, 27 in Experiment 1 and 18 in Experiment 2. Animals were treated on a daily basis with $0.0001 \mathrm{mg} / \mathrm{kg}$ (low dose) or $0.05 \mathrm{mg} / \mathrm{kg}$ (high dose) BPAP starting from the day after subcutaneous tumor inoculation. The control group received saline once every day. Tumors were measured 3 times a week by the same investigator using a digital caliper. Tumor volume was calculated using the following formula: $\mathrm{V}\left(\mathrm{mm}^{3}\right)=($ width $^{2}(\mathrm{~mm}) \times$ length $\left.(\mathrm{mm}) \times \pi\right) / 6$. Mice were terminated by cervical dislocation in ether anesthesia. Tumors were removed, their weight measured, were stored at $-80{ }^{\circ} \mathrm{C}$. The experiment was repeated on SCID mice to determine whether the adaptive immune system has a role in the tumor suppressor effect of BPAP (Experiment 3). Eighteen animals were utilized in this 3 rd study, and were terminated after 28 days.

\section{Materials}

Deprenyl was supplied by Sanofi-Chinoin (Budapest, Hungary) and BPAP by Fujimoto Pharmaceutical Corporation (Osaka, Japan).

\section{Western Blot}

Frozen tumor tissues were homogenized and suspended with lysis buffer (containing: $20 \mathrm{mM}$ Tris $\mathrm{pH}=7.5$, $150 \mathrm{mM} \mathrm{NaCl}, 2 \mathrm{mM}$ EDTA, $0.05 \%$ Triton X-100, 0.5\% Protease Inhibitor Cocktail (P8340, Sigma-Aldrich, St. Louis, MO), $2 \mathrm{mM} \mathrm{Na}_{3} \mathrm{VO}_{4}$ and $10 \mathrm{mM} \mathrm{NaF}$ ). Samples were sonicated and kept on ice before centrifugation at $13000 \mathrm{rpm}$ at $4{ }^{\circ} \mathrm{C}$ for $10 \mathrm{~min}$. Protein concentrations were measured by Bradford method [18]. Thirty $\mu$ g total proteins were mixed with loading buffer containing $\beta$-mercaptoethanol and denatured at $99^{\circ} \mathrm{C}$ for $5 \mathrm{~min}$.

Denatured samples were loaded onto a $10 \%$ SDSpolyacrylamide gel and separated for $40 \mathrm{~min}$ at $200 \mathrm{~V}$. Proteins were transferred to a PVDF membrane with overnight blotting at $4{ }^{\circ} \mathrm{C}$ at a constant $75 \mathrm{~mA}$. Successful blotting was confirmed by Ponceau staining. Blocking procedure was carried out with 5\% non-fat dry milk dissolved in TBS. The primary antibodies applied with their appropriate dilutions are listed in Supplementary Table 1. For negative control, 1\% non-fat dry milk (in TBS) without primary antibody was applied. Incubation was overnight at $4{ }^{\circ} \mathrm{C}$ with gentle shaking. Secondary antibody was anti-rabbit or anti-mouse polyclonal HRP-conjugated antibody (Dako, Glostrup, Denmark) dissolved in 1\% non-fat dry milk (in TBS) applied for $1 \mathrm{~h}$ at room temperature with gentle shaking. For washing $0.05 \%$ Tween 20 in TBS was used for $5 \times 5$ minutes between each step. For detection, SuperSignal West Pico Chemiluminescent Substrate (34,078, Thermo Fischer Scientific, Waltham, MA) was applied. Bands were detected with Kodak Image Station 4000 mm (Kodak, Rochester, NY). The bands were evaluated with GelAnalyzer program.

\section{Statistical Analysis}

All statistical analyses were performed using GraphPad Prism 7.00 software (Graphpad Software Inc., La Jolla, CA, USA). Data were tested for normal distribution using the omnibus normality test of D'Agostino \& Pearson. Significance of changes were tested using a nonparametric test (the MannWhitney U-test) or the Student's t test, depending on the distribution of the data. The independent experimental sets were compared for reproducibility. Only reproducible significant 
changes were considered as significant. Significance was declared at the standard $p<0.05$ level.

\section{Results}

\section{BPAP Inhibits Tumor Growth}

The effect of BPAP on tumor growth was studied in 3 independent experiments. Experiment 1 was performed on $\mathrm{FVB} / \mathrm{N}$ mice using our subcutaneous lung cancer xenograft model [12], where both low and high doses of BPAP significantly inhibited tumor growth $(p<0.05)$ (Fig. 1a). Here, the treatments had only minor effect on the survival of animals (Fig. 1b). In Experiment 2, the entire study was repeated with smaller inoculated tumors aiming to detect changes in both tumor growth and survival of animals. Indeed, BPAP treatment in both doses resulted in reduced tumor size compared to control (Fig. 1c). In harmony with the previous study, tumor volumes decreased with $\sim 40 \%$ and $\sim 50 \%$ after BPAP low- and high- dose treatment, respectively $(p<0.05)$ (Fig. 1c). In addition, BPAP exposure extended the survival of animals compared to control ones (Fig. 1d).

The experiment was repeated again in a SCID mouse strain to see whether the adaptive immune system plays a role in the promotion of the anti-tumor effect of BPAP (Experiment 3 ). In harmony with the previous experiments, BPAP treatment inhibited tumor growth at both concentrations (Fig. 2a). Low-dose BPAP reduced the tumor size by $\sim 40 \%$, the highdose by $\sim 25 \%$ ( $p<0.05$ ), respectively (Fig. $2 b$ ).

\section{Changes in Signaling Pathways Provoked by BPAP}

To explore the impact of BPAP on cell proliferation, regulatory proteins of the G1/S restriction point were examined (Fig. 3). The expression of Cyclin D1 significantly dropped to $50 \%$ and $60 \%$ after the low and high doses of the compound, respectively, and the changes were significant $(p<0.01$ for low and $p<0.001$ for high dose of BPAP). In parallel, CDK4 expression decreased by $50 \%$ and $20 \%$ after

\section{Experiment 1}
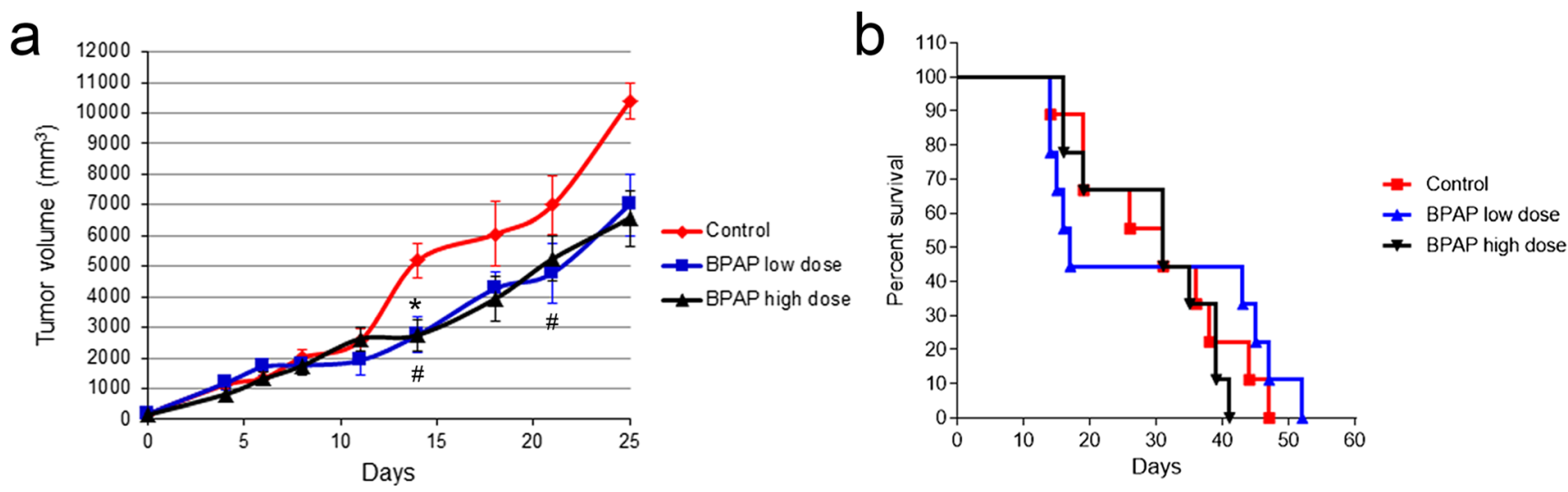

\section{Experiment 2}

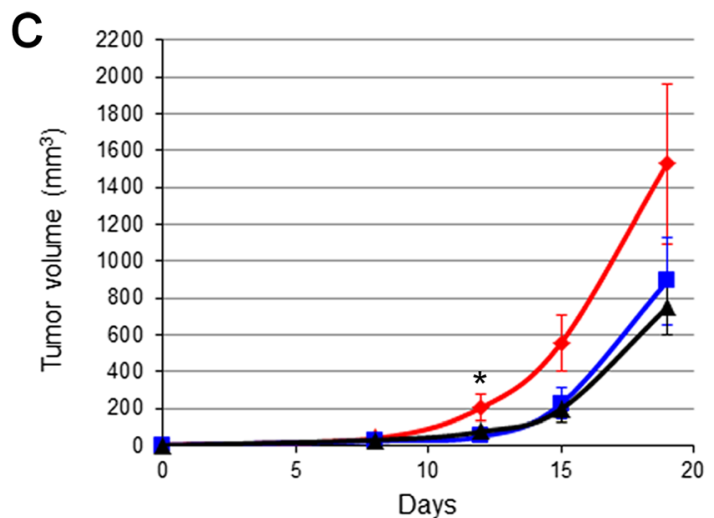

Fig. 1 Growth curve of subcutaneous lung tumor and survival of FVB/N mice. Two independent experiments were performed. Changes in tumor volume (a) and survival rate of the animals (b) in Experiment 1.

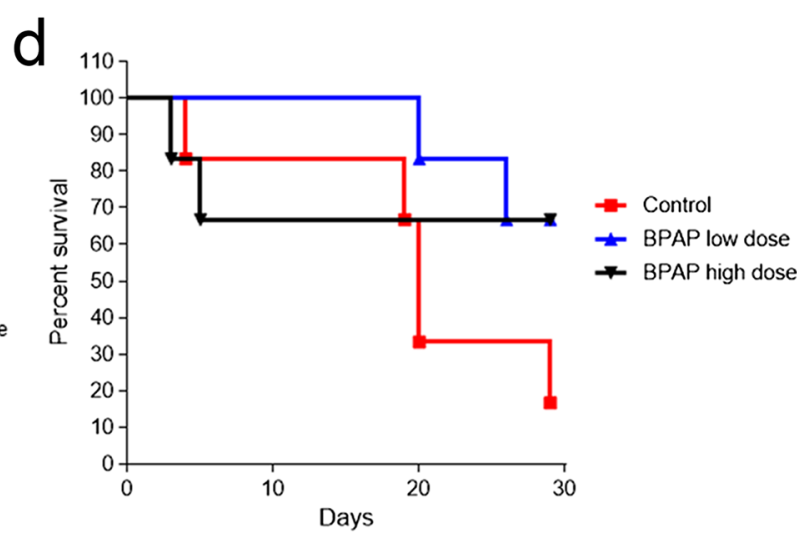

Changes in tumor volume (c) and survival rate (d) in Experiment 2. The data are the mean $\pm \mathrm{SE}$ of the individual groups. $* P<0.05$ for BPAP low dose vs. control; $\# \mathrm{P}<0.05$ for BPAP high dose vs. control 


\section{Experiment 3}

a

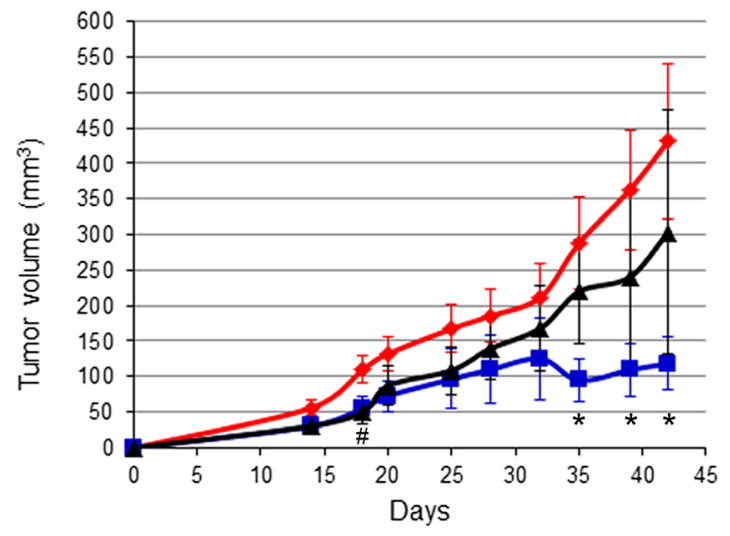

Fig. 2 Growth curve of subcutaneous lung tumor and tumor volume in SCID mice. Temporal changes of tumor volume (a), and the tumor weight (b) at the end of the experiment. The data are the mean $\pm \mathrm{SE}$ of the

low and high doses of BPAP, respectively ( $p<0.001$ for low dose and $p<0.05$ for high dose BPAP). In consequence, retinoblastoma phosphorylation on Ser780 also decreased ( $p<0.01$ for $\mathrm{pRb}$ regarding both doses). The decrease of PCNA level hindered the DNA synthetic activity further, down to $65 \%$ after low dose and to $85 \%$ after high dose of BPAP exposure $(p<0.01$ and $p<0.05$, respectively). In the meantime, the amount of $\mathrm{p} 16^{\mathrm{INK} 4}$ was doubled by the lowdose $(\mathrm{p}<0.01)$, whereas no effect was observable by the highdose BPAP concentration.

Interestingly, the action of low- and high-dose BPAP proved to be different on intracellular signaling pathways (Fig. 4). Peculiarly, the low dose elevated the amount of pAkt phosphorylated in case of both Ser 473 and Thr308 by $100 \%(p<0.01)$, whereas the high dose resulted a decrease by $50 \%(p<0.01)$ and $25 \%$, respectively. The same tendency was found in case of $\mathrm{p}$-Erk 1/2. Low-dose increased p-Erk 1 and 2 levels by $\sim 35 \%$ and $50 \%(p<0.01)$, whereas high-dose

\section{b}

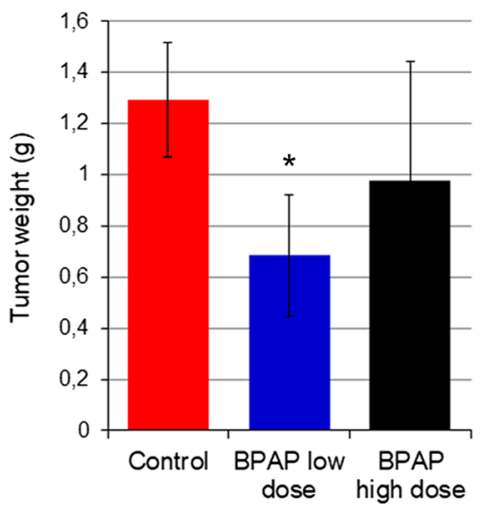

individual groups. ${ }^{*} \mathrm{P}<0.05$ for $\mathrm{BPAP}$ low dose vs. control; $\mathrm{\# P}<0.05$ for BPAP high dose vs. control

decreased both levels by $25 \%$ and $40 \%(p<0.05$ and $p<0.01$, respectively). Enhancement of mTOR signaling upon administration of both BPAP doses resulted in elevated p-S6 amounts by $89 \%$ and $33 \%(\mathrm{p}<0.01$ and $\mathrm{p}<0.05$, respectively). Exposure to low and high doses of BPAP decreased NF-KB level by $10 \%$ and $40 \%$, respectively $(\mathrm{p}<0.01$ for high dose). In addition, low-dose BPAP induced the c-jun level by $15 \%(p<0.001)$, while high-dose reduced it by $30 \%(\mathrm{p}<$ 0.01) (Fig. 4).

\section{BPAP against Cancer-Related Wasting}

Treatment with either low or high doses of BPAP resulted in higher body weight compared to control animals. In Experiment 1, the loss of body mass was delayed, as the BPAP low-dose treated group had $14 \%$ higher body mass on average and the high-dose treated group 22\% higher compared to the control group by the end of the study (Fig. 5a).

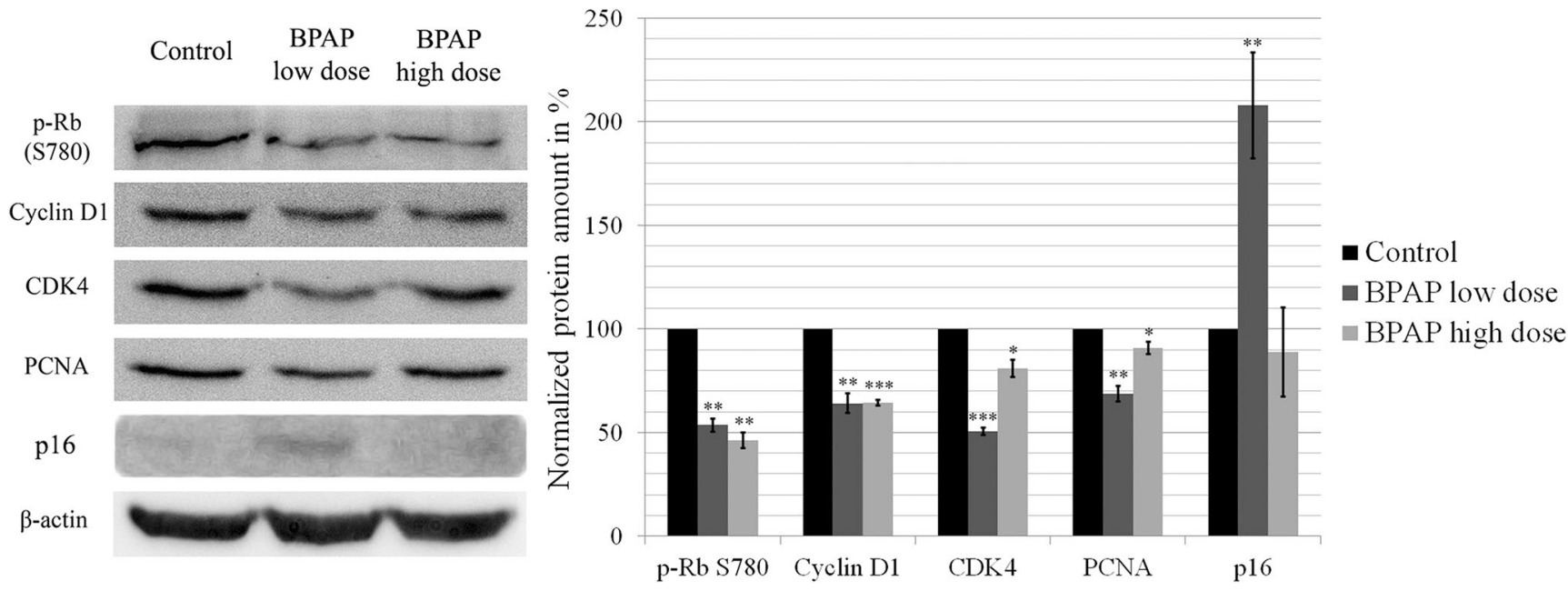

Fig. 3 Western blot analysis of the main cell cycle proteins. The data are the mean $\pm \mathrm{SE}$ of 3 experiments, $* \mathrm{P}<0.05$ and $* * P<0.01$ 

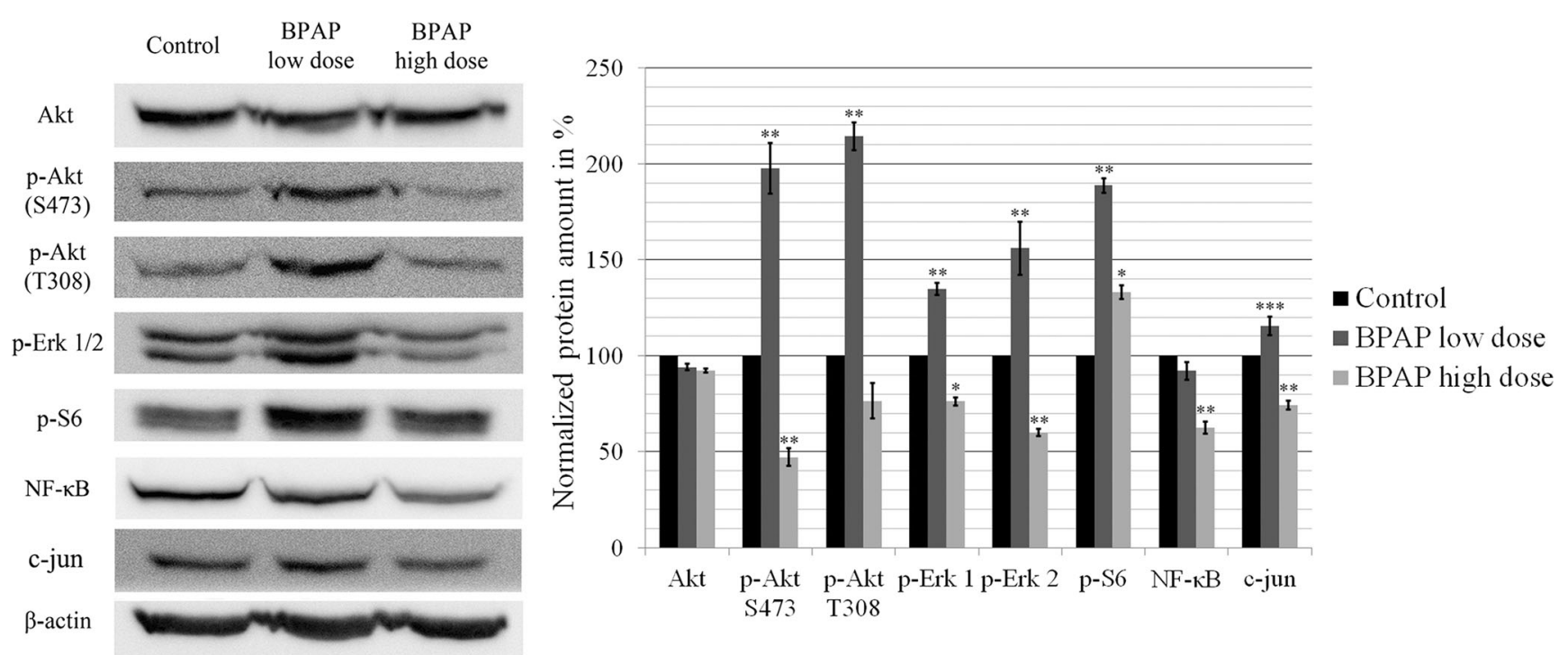

Fig. 4 Western blot analysis of the main signaling pathways. The data are the mean $\pm \mathrm{SE}$ of 3 experiments, $* \mathrm{P}<0.05 ; * * \mathrm{P}<0.01$ and $* * * P<0.001$

In Experiment 2, in which case smaller tumors were inoculated, daily treatment with BPAP led to constant elevation of body weight (Fig. 5b). In contrast, the increase of body mass of tumor-bearing control animals stopped after 30 days. These results suggest that BPAP at least in part is able to compensate the body weight loss of tumor-bearing animals.

\section{Discussion}

In the past decade, the detection of targetable somatic mutations has become essential in the treatment protocol of patients with non-small cell lung cancer [19]. The mutations discovered in the tyrosine kinase domain of EGFR and ALK gene rearrangements, as therapeutic targets have fundamentally

\section{a Experiment 1}

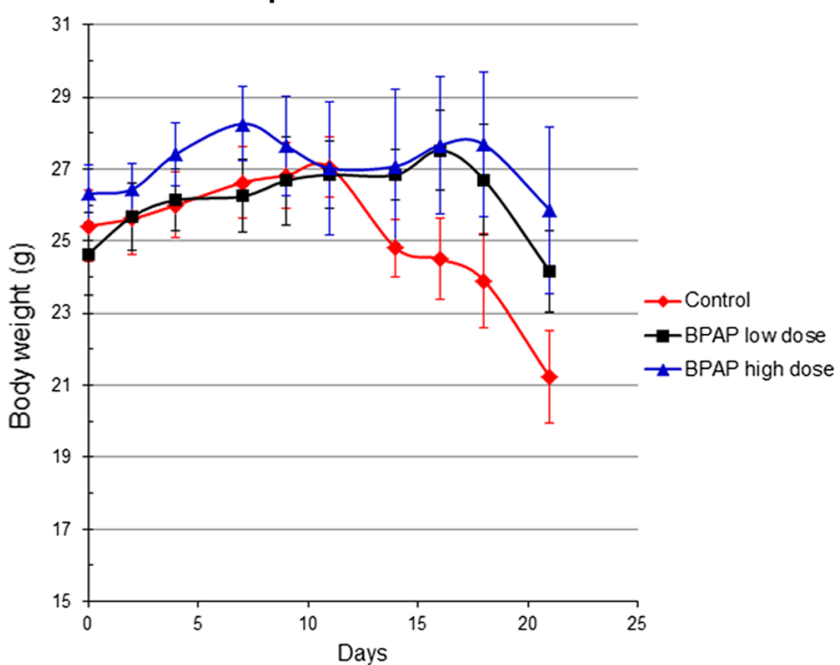

changed the treatment of NSCLC [19, 20]. However, these alterations are responsible for only a proportion of NSCLC cases, so only conventional chemotherapies remain for patients without targetable mutations [21].

Earlier, our research group established and characterized an in vivo mouse NSCLC tumor model system, with wild type KRAS and EGFR genes, mimicking the majority of human lung adenocarcinomas [12]. It came as a surprise that when these tumors were exposed to BPAP the drug exerted a potent inhibitory effect on tumor growth. The substance was applied in a very low concentration range, with the low dose being $0.0001 \mathrm{mg} / \mathrm{kg}$ and the high dose $0.05 \mathrm{mg} / \mathrm{kg}$ bodyweight. Both doses were found to effectively hinder the proliferation of subcutaneously growing tumors. Further, the action mechanism proved to be different in case of both the signaling

Fig. 5 Cancer-related wasting in FVB/N strain. Body mass curves in Experiment 1 (a) and Experiment 2 (b). The data are the mean \pm SE of the individual groups. $\# \mathrm{P}<0.05$ for BPAP high dose vs. control

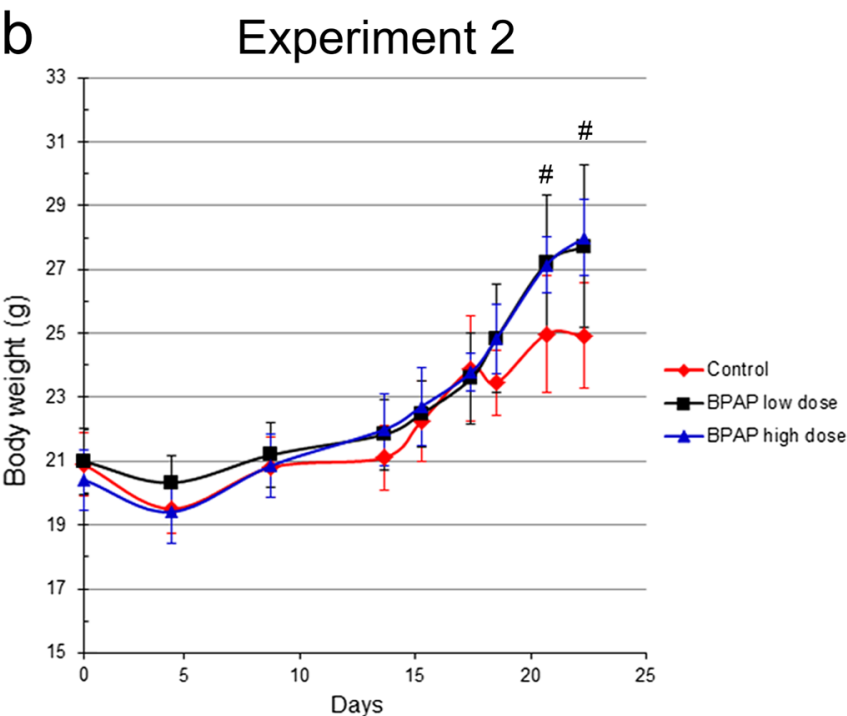


pathways and the cell cycle arrest at G1/S restriction point. In addition, since the effectiveness was detectable in FVB/N and SCID strains as well, the adaptive immune system is likely not involved in the mechanism [22].

To unfold the molecular mechanism behind BPAP's action, we focused our attention on the changes of Akt and MAPK pathways, both known to be the major downstream signaling pathways of growth factor receptors and to play important roles in NSCLC [23]. These two pathways were found to be highly activated in our model system [12, 24]. High-dose BPAP seemed to have a direct and potent inhibitory effect on both p-Akt Ser473 and Thr308 as well as on Erk 1 and 2 (Fig. 6). On the contrary, the low dose provoked activation of both signaling pathways. These findings suggest that the compound utilizes different mechanisms in low and high concentrations. Howsoever, BPAP increased the activity of mTOR, which was indicated by the elevated level of p-S6 where low dose was three times more effective. Indeed, both Akt and Erk activations (observed upon BPAP low-dose exposure) displayed excitatory effect on the mTOR pathway [25].
Inhibition of the overactivated Akt/mTOR pathway is likely an opportunity in the treatment of lung cancer [21, 26].

In spite of the different pathways provoked by low- and high-dose BPAP, the signaling events were finally culminated in cell cycle arrest. Both BPAP doses inhibited the cell cycle at G1/S restriction point since the levels of cyclin D1 and CDK4 became decreased, thus preventing the retinoblastoma from inactivation. The lower PCNA levels observable upon BPAP treatment also point to inhibition of cell proliferation.

In case of low-dose BPAP, the highly stimulated signaling pathways in contrast to the ineffective G1 phase and hindered tumor growth called attention to the mechanism of geroconversion. In this hyper-mitogenic type of arrest, the cell cycle is suppressed by CDK inhibitors (such as $\mathrm{p} 21^{\mathrm{WAF} 1 / \mathrm{CIP} 1}$ or $\mathrm{p} 16^{\mathrm{INK} 4}$ ), but mTOR and MAPK pathways are still active pushing the cell to become hyperthophic, hyper-active and hyper-functional. Activation of mTOR in the presence of cell cycle arrest induces senescent morphology and the loss of ability to proliferate [27-29]. The fact that we observed an increased amount of p16 accompanied by a high level of

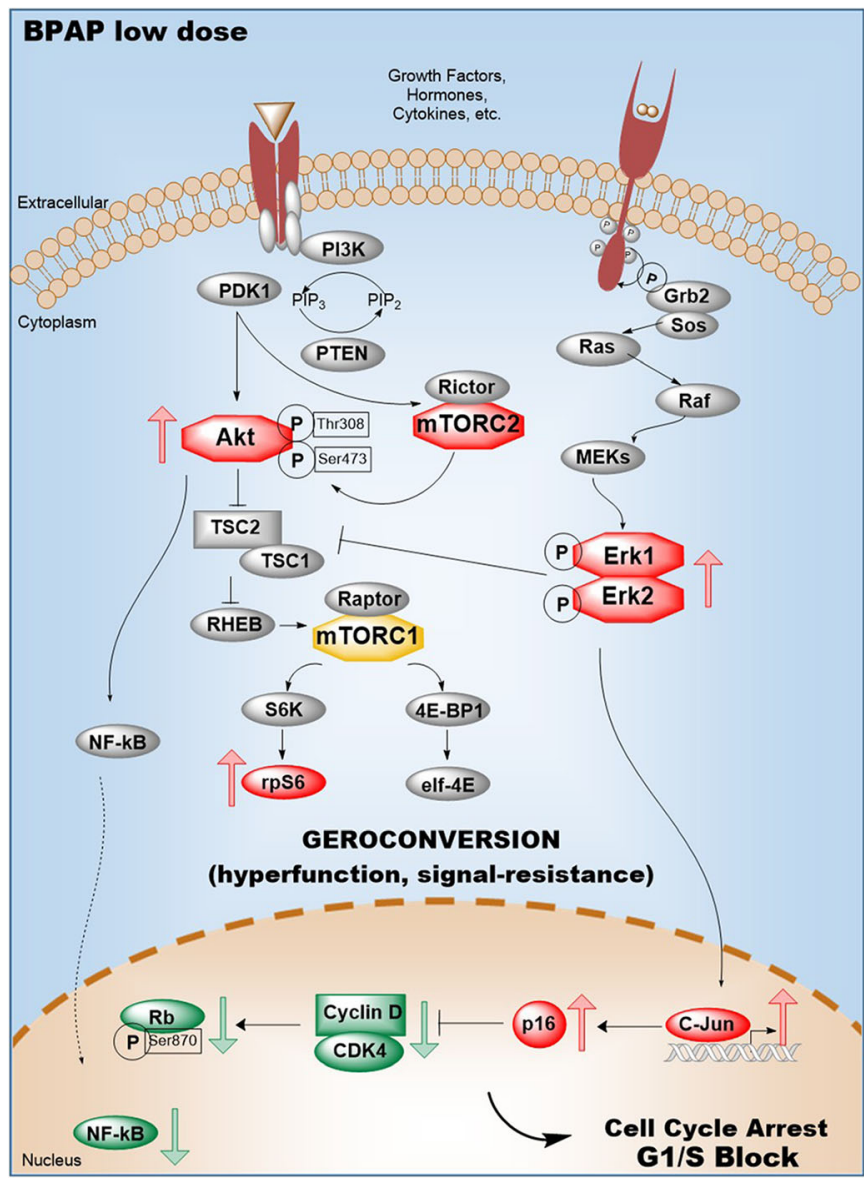

Fig. 6 Schematic illustration of signaling events provoked by low and high dose of BPAP. High-dose BPAP seemed to have a direct inhibitory effect on phospho-Akt as well as on Erk 1 and 2. In contrast, the low dose provoked activation of both signaling pathways. Howsoever, BPAP increased the activity of mTOR, which was indicated by the elevated level

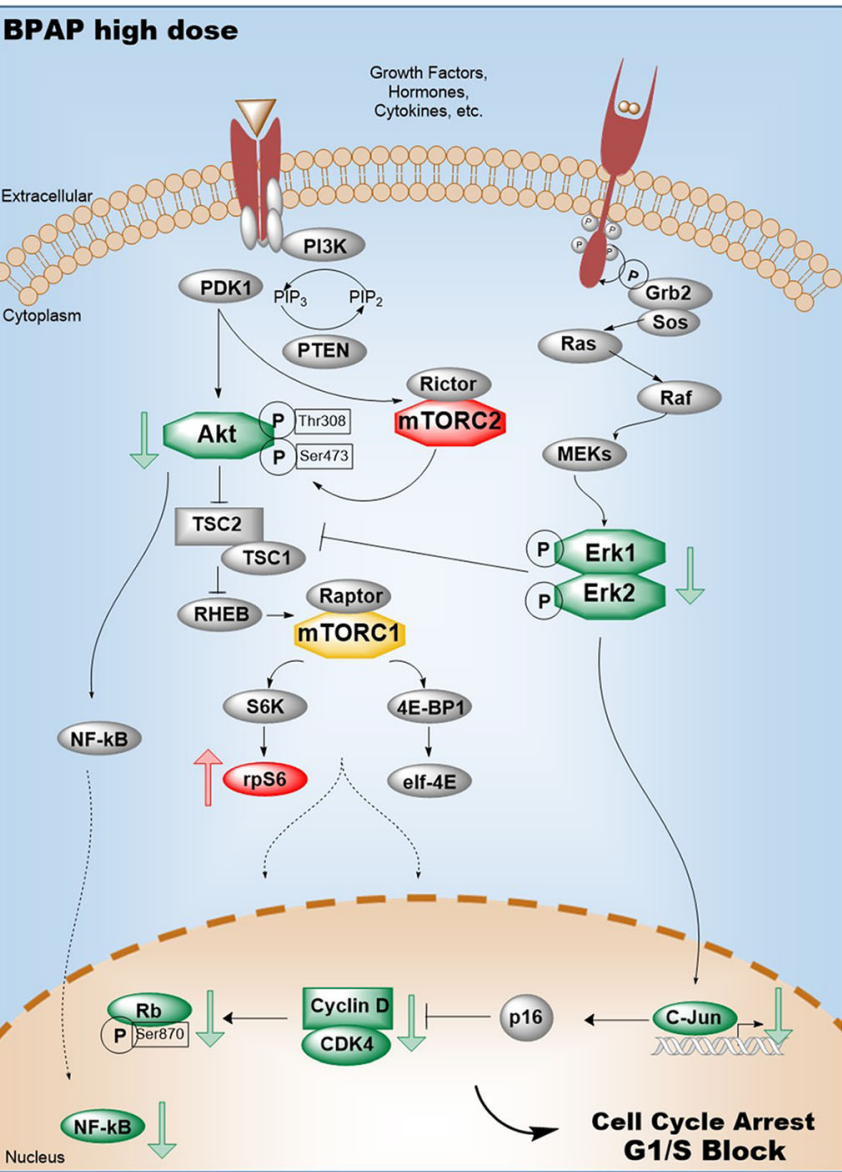

of p-S6. Both BPAP doses inhibited the cell cycle at $\mathrm{G} 1 / \mathrm{S}$ restriction point characterized by decreased cyclin D1 and CDK4 levels preventing the retinoblastoma from inactivation. Exposure to low dose BPAP resulted in elevated activity of the Akt/mTOR and Erk pathways together with p16 ${ }^{\mathrm{INK}}$-induced cell cycle arrest resulted in geroconversion 
mTOR activity supports our presumption that low-dose BPAP provoked geroconversion upon treatment (Fig. 6). Interestingly, similar effect was observed upon exposure to PARP inhibitor in case of liposarcoma and other tumors, however, upregulation of $\mathrm{p} 21^{\mathrm{WAF} 1 / \mathrm{CIP} 1}$ and proteosomal degradation of MDM2 were accompanied by downregulation of CDK4 [30, 31].

The question is, what is the mechanism of p16 upregulation? A recent publication provides evidence that the AP1 factor c-jun is able to interfere with tumorigenesis by protecting the promoter region of $\mathrm{p} 16^{\mathrm{INK} 4 \mathrm{a}}$ from methylation, acting as a "bodyguard" after oncogenic transformation [32]. As we detected strong Erk1/2 activation, with subsequent upregulation of c-jun upon low dose BPAP exposure, it is highly conceivable that c-jun is implicated in the upregulation of $\mathrm{p} 16^{\mathrm{INK}}$.

In contrast with the results observed after low-dose BPAP, the high dose decreased the level of c-jun. $\mathrm{C}$-jun is found to be elevated in $30 \%$ of NSCLC cases and cannot be found in the normal cells of airways [33, 34].

Despite the similar outcome, our data show that BPAP in low and high doses utilizes different mechanisms of action, since the latter exerts direct inhibition of the main signaling pathways (Fig. 6). A further question therefore is, what resulted the activation of p-S6 after BPAP highdose administration? [35, 36].

Cancer cachexia is a terminal state in which patients lose their body fat and muscle weight rapidly as compared with immune system failures and metabolic dysfunctions [37]. Both low- and high-dose BPAP exposure had a beneficial effect on cachexia. High-dose BPAP showed better protection, saving $22 \%$ more of the animal's body mass. $\mathrm{NF}-\mathrm{KB}$ is a key regulator of the events implicated in the development of cachexia [38]. NF-KB has a role also in chemotherapy resistance, thus its inhibition may potentiate the efficacy of the therapy [39].

\section{Conclusions}

BPAP is a potent enhancer substance related to certain signaling events in the central nervous system. In a longevity study, it was discovered that the substance is also effective against certain types of cancers, showing the most promising results in case of lung cancer. In our study, the effects of two different doses of BPAP were studied in a newly developed EGFR wild type mouse lung adenocarcinoma xenograft. Both doses showed good results in tumor and cachexia inhibition, although seemingly having different mechanisms of action. High dose of BPAP showed direct inhibition on the main signaling pathways, whereas the low dose seemed to initiate geroconversion. Elevated activity of the mTOR pathway together with $\mathrm{p} 16^{\mathrm{INK}}$-induced cell cycle arrest resulted in geroconversion, which is a senescent state accompanied by loss of cell proliferation.

In view of the low toxicity and confirmed antitumor effect of BPAP in case of experimental lung adenocarcinoma, this novel compound deserves further attention.

Acknowledgements The authors would like to thank Fujimoto Pharmaceutical Corporation (Osaka, Japan) for the generous gift of BPAP substance, András Sztodola for his valuable help in the animal nursing and Elvira Kálé Rigóné for language correction. This work was supported by National Scientific Research Fund (grant no: 105763).

Data Availability Statement The datasets used and/or analyzed during the current study available from the corresponding author on reasonable request.

Funding Open access funding provided by Semmelweis University (SE). This work was supported by National Scientific Research Fund (grant no: 105763).

\section{Compliance with Ethical Standards}

Conflicts of Interest The authors declare no conflict of interest.

Ethical Approval All procedures performed in studies involving animals were in accordance with the ethical standards of the institution or practice at which the studies were conducted.

Abbreviation $A k t$, protein kinase $\mathrm{B} ; A L K$, anaplastic lymphoma kinase; $B P A P$, (2R)-1-(1-Benzofuran-2-yl)-N-propylpentan-2-amine; $C D K 4$, cyclin-dependent kinase 4; EDTA, ethylene diamine tetraacetic acid; $E G F R$, epidermal growth factor receptor; $H R P$, horseradish peroxidase; KRAS, Kirsten Rat Sarcoma virus oncogene; $M A O-B$, monoamine-oxidase B; $M D M 2$, mouse double minute 2 homolog; $m T O R$, mechanistic target of rapamycin; NSCLC, non-small cell lung cancer; $P A R P$, poly ADP ribose polymerase; $P C N A$, ploriferating cell nuclear antigen; $P V D F$, polyvinylidene difluoride; $R b$, retinoblastoma; $S C I D$, severe combined immunodeficiency; TBS, Tris-buffered saline

Open Access This article is distributed under the terms of the Creative Commons Attribution 4.0 International License (http:// creativecommons.org/licenses/by/4.0/), which permits unrestricted use, distribution, and reproduction in any medium, provided you give appropriate credit to the original author(s) and the source, provide a link to the Creative Commons license, and indicate if changes were made.

\section{References}

1. Knoll J, Magyar K (1972) Some puzzling effects of monoamine oxidase inhibitors. Adv Biochem Psychopharmacol 5:393-408

2. Heinonen EH, Myllyla V (1998) Safety of selegiline (deprenyl) in the treatment of Parkinson's disease. Drug Saf 19:11-22

3. Knoll J (1988) The striatal dopamine dependency of life span in male rats. Longevity study with (-)deprenyl. Mech Ageing Dev 46: 237-262

4. Freisleben HJ, Lehr F, Fuchs J (1994) Lifespan of immunosuppressed NMRI-mice is increased by deprenyl. J Neural Transm Suppl 41:231-236 
5. Ruehl WW, Entriken TL, Muggenburg BA, Bruyette DS, Griffith WC, Hahn FF (1997) Treatment with L-deprenyl prolongs life in elderly dogs. Life Sci 61:1037-1044

6. Knoll J, Knoll B, Torok Z, Timar J, Yasar S (1992) The pharmacology of 1-phenyl-2-propylamino-pentane (PPAP), a deprenylderived new spectrum psychostimulant. Arch Int Pharmacodyn Ther 316:5-29

7. Knoll J, Yoneda F, Knoll B, Ohde H, Miklya I (1999) (-)1(Benzofuran-2-yl)-2-propylaminopentane, [(-)BPAP], a selective enhancer of the impulse propagation mediated release of catecholamines and serotonin in the brain. Br J Pharmacol 128:1723-1732

8. Maruyama W, Yi H, Takahashi T, Shimazu S, Ohde H, Yoneda F, Iwasa K, Naoi M (2004) Neuroprotective function of R-(-)-1(benzofuran-2-yl)-2-propylaminopentane, [R-(-)-BPAP], against apoptosis induced by $\mathrm{N}$-methyl(R)salsolinol, an endogenous dopaminergic neurotoxin, in human dopaminergic neuroblastoma SHSY5Y cells. Life Sci 75:107-117

9. Gaszner P, Miklya I (2006) Major depression and the synthetic enhancer substances, (-)-deprenyl and R-(-)-1-(benzofuran-2-yl)2-propylaminopentane. Prog Neuro-Psychopharmacol Biol Psychiatry 30:5-14

10. Knoll J, Miklya I (2016) Longevity study with low doses of selegiline/(-)-deprenyl and (2R)-1-(1-benzofuran-2-yl)-Npropylpentane-2-amine (BPAP). Life Sci 167:32-38

11. Knoll J, Baghy K, Eckhardt S, Ferdinandy P, Garami M, Harsing LG Jr, Hauser P, Mervai Z, Pocza T, Schaff Z, Schuler D, Miklya I (2017) A longevity study with enhancer substances (selegiline, BPAP) detected an unknown tumor-manifestation-suppressing regulation in rat brain. Life Sci 182:57-64

12. Mervai Z, Egedi K, Kovalszky I, Baghy K (2018) Diethylnitrosamine induces lung adenocarcinoma in FVB/N mouse. BMC Cancer 18:157

13. Siegel R, Ma J, Zou Z, Jemal A (2014) Cancer statistics, 2014. CA Cancer J Clin 64:9-29

14. Ferlay J, Steliarova-Foucher E, Lortet-Tieulent J, Rosso S, Coebergh JW, Comber H, Forman D, Bray F (2013) Cancer incidence and mortality patterns in Europe: estimates for 40 countries in 2012. Eur J Cancer 49:1374-1403

15. Molina JR, Yang P, Cassivi SD, Schild SE, Adjei AA (2008) Nonsmall cell lung cancer: epidemiology, risk factors, treatment, and survivorship. Mayo Clin Proc 83:584-594

16. Subramanian J, Govindan R (2007) Lung cancer in never smokers: a review. J Clin Oncol Off J Am Soc Clin Oncol 25:561-570

17. Mudduluru G, Walther W, Kobelt D, Dahlmann M, Treese C, Assaraf YG, Stein U (2016) Repositioning of drugs for intervention in tumor progression and metastasis: old drugs for new targets. Drug Resist Updat 26:10-27

18. Bradford MM (1976) A rapid and sensitive method for the quantitation of microgram quantities of protein utilizing the principle of protein-dye binding. Anal Biochem 72:248-254

19. Chan BA, Hughes BG (2015) Targeted therapy for non-small cell lung cancer: current standards and the promise of the future. Transl Lung Cancer Res 4:36-54

20. Lynch TJ, Bell DW, Sordella R, Gurubhagavatula S, Okimoto RA, Brannigan BW, Harris PL, Haserlat SM, Supko JG, Haluska FG, Louis DN, Christiani DC et al (2004) Activating mutations in the epidermal growth factor receptor underlying responsiveness of nonsmall-cell lung cancer to gefitinib. N Engl J Med 350:2129-2139
21. Pallis AG (2012) A review of treatment in non-small-cell lung Cancer. Eur Oncol Haematol 8(4):208-212

22. Bosma MJ, Carroll AM (1991) The SCID mouse mutant: definition, characterization, and potential uses. Annu Rev Immunol 9: 323-350

23. Brambilla E, Gazdar A (2009) Pathogenesis of lung cancer signalling pathways: roadmap for therapies. Eur Respir J 33:1485-1497

24. Yip PY (2015) Phosphatidylinositol 3-kinase-AKT-mammalian target of rapamycin (PI3K-Akt-mTOR) signaling pathway in nonsmall cell lung cancer. Transl Lung Cancer Res 4:165-176

25. Mendoza MC, Er EE, Blenis J (2011) The Ras-ERK and PI3KmTOR pathways: cross-talk and compensation. Trends Biochem Sci 36:320-328

26. Fumarola C, Bonelli MA, Petronini PG, Alfieri RR (2014) Targeting PI3K/AKT/mTOR pathway in non small cell lung cancer. Biochem Pharmacol 90:197-207

27. Blagosklonny MV (2014) Geroconversion: irreversible step to cellular senescence. Cell Cycle 13:3628-3635

28. Demidenko ZN, Blagosklonny MV (2008) Growth stimulation leads to cellular senescence when the cell cycle is blocked. Cell Cycle 7:3355-3361

29. Blagosklonny MV (2012) Cell cycle arrest is not yet senescence, which is not just cell cycle arrest: terminology for TOR-driven aging. Aging (Albany NY) 4:159-165

30. Yoshida A, Diehl JA (2015) CDK4/6 inhibitor: from quiescence to senescence. Oncoscience 2:896-897

31. Kovatcheva M, Liu DD, Dickson MA, Klein ME, O'Connor R, Wilder FO, Socci ND, Tap WD, Schwartz GK, Singer S, Crago AM, Koff A (2015) MDM2 turnover and expression of ATRX determine the choice between quiescence and senescence in response to CDK4 inhibition. Oncotarget 6:8226-8243

32. Kollmann K, Heller G, Sexl V (2011) c-JUN prevents methylation of p16(INK4a) (and Cdk6): the villain turned bodyguard. Oncotarget 2:422-427

33. Wisdom R, Johnson RS, Moore C (1999) c-Jun regulates cell cycle progression and apoptosis by distinct mechanisms. EMBO J 18: 188-197

34. Szabo E, Riffe ME, Steinberg SM, Birrer MJ, Linnoila RI (1996) Altered cJUN expression: an early event in human lung carcinogenesis. Cancer Res 56:305-315

35. Laplante M, Sabatini DM (2012) mTOR signaling in growth control and disease. Cell 149:274-293

36. Saxton RA, Sabatini DM (2017) mTOR signaling in growth, metabolism, and disease. Cell 169:361-371

37. Kumar NB, Kazi A, Smith T, Crocker T, Yu D, Reich RR, Reddy K, Hastings S, Exterman M, Balducci L, Dalton K, Bepler G (2010) Cancer cachexia: traditional therapies and novel molecular mechanism-based approaches to treatment. Curr Treat Options in Oncol 11:107-117

38. Zhou W, Jiang ZW, Tian J, Jiang J, Li N, Li JS (2003) Role of NFkappaB and cytokine in experimental cancer cachexia. World $\mathrm{J}$ Gastroenterol 9:1567-1570

39. Denlinger CE, Rundall BK, Jones DR (2004) Modulation of antiapoptotic cell signaling pathways in non-small cell lung cancer: the role of NF-kappaB. Semin Thorac Cardiovasc Surg 16:28-39

Publisher's Note Springer Nature remains neutral with regard to jurisdictional claims in published maps and institutional affiliations. 